\title{
The effectiveness of foreign exchange interventions under a floating exchange rate regime for the Turkish economy: a post-crisis period analysis
}

\author{
Özge Akinci , Olcay Yücel Çulha , Ümit Özlale \& Gülbin Şahinbeyoğlu
}

To cite this article: Özge Akinci , Olcay Yücel Çulha , Ümit Özlale \& Gülbin Șahinbeyoğlu (2006) The effectiveness of foreign exchange interventions under a floating exchange rate regime for the Turkish economy: a post-crisis period analysis, Applied Economics, 38:12, 1371-1388, DOI: $10.1080 / 00036840500392995$

To link to this article: http://dx.doi.org/10.1080/00036840500392995

册 Published online: 02 Feb 2007.

Submit your article to this journal $[\pi$

Џ Article views: 89

Q View related articles $\llbracket$

4 Citing articles: 5 View citing articles 


\title{
The effectiveness of foreign exchange interventions under a floating exchange rate regime for the Turkish economy: a post-crisis period analysis
}

\author{
Özge Akinci ${ }^{\mathrm{a}}$, Olcay Yücel Çulha ${ }^{\mathrm{a}}$, Ümit Özlale ${ }^{\mathrm{b}, *}$ and \\ Gülbin Şahinbeyoğlu ${ }^{\mathrm{a}}$ \\ ${ }^{a}$ Research Department, Central Bank of the Republic of Turkey, Turkey \\ ${ }^{\mathrm{b}}$ Department of Economics, Bilkent University, Turkey
}

The reported study has two purposes: first, it attempts to improve the literature on foreign exchange interventions of the central banks for the emerging market economies, an area not previously studied in detail. The Turkish economy in the post-crisis period constitutes a good example in this context. Second, it proposes a new methodology, a time-varying parameter model, to analyse the effectiveness of the foreign exchange interventions. When the results from such an exercise are compared with those obtained from an event-study analysis, it is found that purchasebased interventions seem to be successful, especially after stabilization of the financial markets. In that sense, an asymmetry is detected regarding the effectiveness of interventions. Concerning the relationship between interest rates and exchange rates, it is found that the uncovered interest rate parity condition operates in an unconventional way, supporting the views put forward by recent emerging markets literature.

\section{Introduction}

Although there has been a growing interest regarding the effectiveness of foreign exchange market interventions conducted by the central banks, few studies concentrate on the emerging market economies. ${ }^{1}$ However, characterized as having shallow foreign exchange markets, which exhibit excess sensitivity to speculative short-term capital flows, emerging country cases can reveal important information about the effectiveness of foreign exchange interventions by the central banks, in particular, after intensified attempts of these emerging market economies to implement inflation-targeting regimes - either in explicit or implicit forms - the changing roles of both short-term and long-term exchange rate dynamics in the monetary policymaking process make this issue even more appealing: On the one hand, due to high exchange rate pass-through, there is a close link between exchange rate and inflation. When the exchange rate variability affect the price dynamics negatively, then it will create an incentive for

*Corresponding author. E-mail: ozlale@bilkent.edu.tr

${ }^{1}$ Domac and Mendoza (2002), Agcaer (2003), Guimaraes and Karacadag (2004), Herrera and Ozbay (2005) are exceptions. 
the inflation-targeting countries to intervene in the foreign exchange market to reduce excess volatility. Arize and Malindretos (1997) show that exchange rate variability is a factor contributing to inflation variability. On the other hand, inflation-targeting regimes explicitly state interest rates as the main monetary policy instrument where no exchange rate target is to be followed unless there is distortion on price dynamics. The so-called 'impossible trinity' also implies this case: in the case of free capital mobility, an independent monetary policy cannot be followed if there is an incentive for policymakers to defend a particular exchange rate target. As background to these constraints and the highly volatile nature of the foreign exchange rate market, the above discussion implies that analysing foreign exchange interventions of the central banks in emerging markets is not straightforward at all.

There are two dominant and competing methodologies to test the effectiveness of the foreign exchange interventions. The first one is the Generalized Autoregressive Conditional Heteroscedasticity (GARCH) framework, where the effects of interventions on both the mean and the conditional variance of exchange rates can be tested. However, as discussed by Fatum and Hutchison (1999), given the highly volatile nature of the exchange rates on a day-to-day basis, intervention operations are relatively infrequent. Therefore, the connection between foreign exchange market interventions and the movements of exchange rates are not easy to measure with relevant time series techniques. In fact, the numerous empirical studies based on the time series techniques produce mixed results and there is no strong evidence that sterilized foreign exchange market interventions systematically affect the exchange rate.

Based on the above criticisms, the 'event study' approach as proposed by Fatum and Hutchison (1999) emerged as an alternative framework to test the effectiveness of foreign exchange interventions. ${ }^{2}$ Employed mainly in the field of finance, 'event study' makes it possible to analyse the impact of each single intervention on the exchange rate dynamics with a special reference to the nature of the period over which the events are defined. Also, such an approach does not require the imposition of a structural model for the exchange rate determination. However, 'event study' has also some limitations. First, the effect of fundamentals and the changes in the other variables - such as the arrivals of the news regarding the changes in the policies - can hardly be controlled. There are several studies arguing that macro-economic news announcement affect the volatility of foreign exchange rates. Among them, Kim (1999) focuses on the Australian economy and shows that current account deficit, CPI and unemployment rate news announcements significantly increase the conditional volatility of the exchange rate changes of the Australian dollar on the days of the announcement. Second, in the case of an effective intervention, the particular channel of transmission through which foreign exchange intervention operates cannot be identified. In other words, such an approach stops short of explaining why foreign exchange intervention is effective and which factors cause interventions to be more effective.

This paper takes the above discussion as its starting point and proposes an alternative methodology, a time-varying parameter model, to test the effectiveness of foreign exchange interventions for an emerging market, namely the Turkish economy, in the post-crisis period. An 'event study' exercise will also be performed to test the robustness of the results obtained from the time-varying parameter model. As will become clear in the following sections, a timevarying parameter framework is not likely to face most of the criticisms that are brought especially to GARCH models. By allowing the parameters of the model to vary over time, one might hope to capture much more of the volatility and structural change that seem to characterize the emerging market economies. Depending on the state of the economy, we may observe both successful and unsuccessful interventions for the sample period, which a typical GARCH model fails to detect. In particular, in terms of the operation of the uncovered interest rate parity condition, we may obtain some important results. As discussed by Bergin (2004), the literature on the New Open Economy Macroeconomics tries to analyse the frequent deviations from the uncovered interest rate parity condition, especially for the emerging market cases. A time-varying parameter framework has the potential to figure out the periods where such deviations are observed. Therefore, this methodology is superior to a GARCH model, where the relationship between the exchange rate and the other variables - including intervention - is assumed to stay intact over time. It should also reveal important information about the dynamics of the exchange rates, which event study analysis fails to capture.

Finally, the Turkish economy stands out as an interesting case, especially in terms of foreign exchange interventions. While the post-crisis period in 2001 can be characterized by an intense sale of foreign exchange to the financial markets,

${ }^{2}$ Event study is discussed by MacKinlay (1997) in detail. 
a significant appreciation of the domestic currency is observed along with sharp decreases in the interest rates in the following years. ${ }^{3}$ Therefore, the CBRT mostly conducted foreign exchange purchases from the market. The changes in the stability of the political system, the questions regarding the debt sustainability of the Treasury as well as the attempts to shift to an explicit inflation-targeting framework are other important developments that make the Turkish case even more appealing.

The outline of this study is as follows: The next two sections present a brief literature survey and an overview of the foreign exchange market of the Turkish economy in the post-crisis period, with special emphasis on the interventions conducted by the CBRT. Next, the estimation methodologies are introduced and the results from the time-varying parameter model and the event study are compared. The final section concludes.

\section{Literature Survey}

Since most of the central banks of both industrialized and emerging market economies follow sterilized interventions, i.e. the money supply remains unchanged via open market operations or swaps, the literature on the effectiveness of these interventions focus mainly on those types of interventions. As mentioned in Sarno and Taylor (2001) as well as Spolander (1999), there are mainly three channels through which sterilized interventions operate: portfolio balance effect, signaling effect and noise trading effect.

\section{The portfolio balance channel}

Portfolio balance channel states that, following the sterilized intervention, although the money supply and interest rates remain unchanged, there may be significant changes in the composition of agents' portfolios since central banks trade domestic assets for sterilization. For example, after a foreign exchange purchase operation, the central bank sells domestic assets to absorb the excess domestic currency in the market. Such an action will change the portfolio composition of the agents in the economy since an increase in the supply of domestic assets will lead to a fall in their relative prices, which in turn, will lead to a depreciation of the domestic currency. However, for portfolio balance effect to be valid, agents should view domestic assets and foreign assets as imperfect substitutes.

${ }^{3}$ The sales in 2001 were mostly in the form of auctions.
As reviewed in Edison (1993), much of this literature suggests that the exchange rate effects of intervention through the portfolio balance channel are very small in size. On the contrary, Dominguez and Frankel (1993), using survey data on US dollarGerman mark and US dollar-Swiss frank exchange rate expectations, find that intervention variables have significant explanatory power in a regression for the risk premium. Providing strong support in favour of a significant portfolio balance effect and, therefore, effectiveness of intervention, they challenge the conventional wisdom that portfolio balance channel is ineffective.

\section{The signaling channel}

The signaling channel has received much more attention recently. The basic idea is that sterilized interventions of the central banks convey important information about the future course of monetary policy. In this context, it should be assumed that central banks have superior information relative to other market participants, and, more importantly, they are willing to share this superior information by sending signals to the market via foreign exchange operations. As a result, foreign exchange intervention has an impact on exchange rate dynamics because agents in the economy revise their expectations about the future monetary policy actions. The literature also provides empirical support for the validity of the signaling channel. Lewis (1995), examining the period from 1980 to 1995 for the Federal Reserve foreign exchange rate interventions, finds evidence that interventions help to predict monetary policy variables. In a later study, Kaminsky and Lewis (1996) provide evidence that foreign exchange interventions actually predict future monetary policies but the sign implied by the signaling hypothesis is opposite when the interventions are followed by inconsistent movements in monetary policy. Analysing the relationship between the Federal Reserve's monetary policy operations, foreign exchange interventions and the exchange rates, Bonser-Neal et al. (1998) find that the exchange rate generally responds immediately to monetary policy actions. The authors also find evidence that the interventions, cumulative over the previous two weeks, signal future changes in the federal funds target rate over the sample period.

\section{The noise trading approach}

Similar to the signaling channel, the noise trading approach is also viewed as an alternative channel 
through which foreign exchange interventions are effective. As argued by Hung (1991, 1997), the basic idea is to affect the trend-following behaviour of noise traders by intervening unexpectedly on technically overbought or oversold markets. By giving these noise traders a sign or excuse to reverse their position at a time, central banks may be able to reverse the present trend of the exchange rate. Although the noise trading channel and signaling channel may seem identical, there is no policy intention in the former: central banks forces traders to take or modify their exchange rate positions.

However, the link between the foreign exchange interventions and the exchange rate dynamics is not clear. There is mixed evidence regarding the impact of interventions on the exchange rate movements in the empirical studies. Among these, Dominguez (1998) examines the effects of the US, German and Japanese monetary and intervention policies on US dollarGerman mark and US dollar-Japanese yen exchange rate volatility over the 1977 to 1994 period. The results indicate that intervention operations generally increase exchange rate volatility. Bonser-Neal and Tanner (1996) examine the effects of the central bank interventions on the ex ante volatility of the same currencies, from 1985 to 1991 . They find little support for the hypothesis that central bank intervention is associated either with a positive change in the ex ante exchange rate volatility or with no change at all. In a more recent study, Ramchander and Sant (2002) investigate the relationship between FED's interventions and exchange rate volatility by focusing on future prices. Their results indicate that there is no relationship between interventions and exchange rate volatility for the dollar-mark, while interventions are found to be negatively associated with changes in dollar-yen volatility during the 1985 to 1993 period.

\section{Types of intervention}

Types of intervention are commonly classified under three categories: coordinated versus uncoordinated, large versus small, and successive versus isolated. The common feature of these categories in terms of the signaling channel is that they provide information about the central banks' strength and credibility.

Coordinated interventions, as stated in Sarno and Taylor (2001), occur when two or more central banks intervene simultaneously in the market in support of the same currency, according to an explicit or implicit international agreement of cooperation. The coordinated interventions are more likely to convince speculators that the signaled policy is credible relative to an individual intervention. Such a case implies that official intervention coordination may be favourable for the central banks with relatively low reputation or credibility. Successive interventions, on the other hand, indicate the situation in which central banks intervene in the exchange rate markets for consecutive days. More specifically, these interventions signal that the bank has decided to sustain its intervention policy as long as necessary and strong enough to do so. However, it may also imply that an intervention followed by others has not fulfilled its initial goal, which may be perceived as an indication of weakness. Finally, the size of interventions also indicates the strength of the central banks to push the market in the desired direction. Large interventions can be considered as being more credible. Therefore, if each intervention in the successive operations is small, it may send a signal such that the resources devoted to defend the exchange rate are limited. However, if only the presence of central bank matters, then successive small interventions can be as effective as a single large operation.

The empirical findings regarding the abovementioned types of interventions are mixed. Beine and Szafarz (2003) and Fatum and Hutchison (2003) examine the effectiveness of Bank of Japan's interventions against US dollar by considering the types of intervention and find that small unilateral interventions are counterproductive while large and sustained ones influence the foreign exchange market in the desired directions. Large-scale coordinated interventions have also increased the likelihood of success. Fatum (2000) states similar results for Bundesbank's interventions against the US dollar. For the Reserve Bank of Australia's operations, Kim et al. (1999) find that the magnitude and/or the successive pattern of the interventions partly affect the success of the operations in the period 1983 to 1997, while McLaren (2002) finds them not to be effective for the period 1991 to 1998.

\section{The Turkish Economy in the Post-Crisis Period}

After the collapse of the exchange rate-based stabilization program in February 2001, the Turkish economy experienced its deepest financial crisis. Therefore, with the support of the IMF, some regulatory and structural reforms were immediately implemented. First, the CBRT announced that a floating exchange rate regime was to be implemented. Next, the government presented an ambitious structural agenda focusing on immediate banking sector restructuring, transparent public accounting, 
enhanced privatization and promoted foreign direct investment. In this respect, fiscal policy was tightened in order to stabilize the increasing debt stock of the public sector, which was also shifted by the large amount of costs of the banking sector clean up. Furthermore, the control of the CBRT over the short-term interest rates was strengthened in line with the adoption of the floating exchange rate regime.

Under the new regime, more specifically, the primary objective of CBRT was stated as bringing inflation down to single digits over the medium term and maintaining price stability. A monetary framework, setting performance criteria on the level of base money consistent with the inflation target and growth projections, has been developed. CBRT has also announced that it would raise (decrease) money market rates if inflation indicators suggested that the disinflation process is in jeopardy (good performance), even if the base money was close to its targets. In this respect, the CBRT explicitly stated that it would also stand ready to intervene in the market to smooth out excessive short-run exchange rate volatility and conduct foreign exchange purchase auctions to improve the international reserve position conditional on the strength of the balance of payments position and the reverse currency substitution. Therefore, as a result, the implicit inflationtargeting regime that the CBRT adopted in the post-crisis period was to be supported by foreign exchange interventions.

Finally, it is also important to discuss the characteristics of these foreign exchange interventions in the post-crisis period. In fact, in terms of interventions, this period can be divided into two phases. In the first phase, the detrimental results of the financial crisis were still in effect along with an unstable political state. Therefore, this period witnessed a volatile exchange rate and depreciating Turkish lira. Since these developments could negatively affect both the price dynamics and the financial sector, the CBRT conducted foreign exchange sale operations to the market, in line with its monetary policy objectives. In some of the periods, foreign exchange auctions also accompanied these interventions. In the second phase, however, the financial as well as the foreign exchange markets were relatively stabilized. Also, with the increase in the short-term capital flows, this period experienced an immediate and persistent appreciation of the domestic currency, which, this time, led the CBRT to conduct intense foreign exchange purchase operations. By the end of 2004, the CBRT officially announced that it would start once again conducting foreign exchange purchase operations, mainly in the form of auctions and, if necessary, in the form of interventions. As a result, the foreign exchange interventions of the CBRT during the inflationtargeting regime have not yet come to a halt.

\section{Methodology and Results}

This section first compares the methodologies that dominate the literature on foreign exchange interventions. Then, a time-varying parameter model is discussed as an alternative framework. Finally, the results that are obtained from an event-study analysis as well as the time varying parameter model are presented.

\section{Methodology}

Parametric versus non-parametric techniques. As mentioned in the Introduction, time series techniques and the event study approach emerge as the two competing methodologies to analyse the effectiveness of the foreign exchange interventions. Although the latter methodology has received more support recently, the time series methods have also been widely used. Such a methodology allows us to identify the channels, namely the signaling channel or the portfolio balance channel, through which foreign exchange interventions operate.

However, as reported in Fatum and Hutchison (1999), given the highly volatile nature of the exchange rates on a day-to-day basis, intervention operations are relatively infrequent. Therefore, the connection between the sterilized foreign exchange market interventions and the dynamics of the exchange rates are not easy to measure with relevant time series techniques. In fact, the numerous empirical studies based on the time series techniques produce mixed results and there is no strong evidence that sterilized foreign exchange market interventions systematically affect the exchange rate (see Section II). Moreover, these methods necessitate the estimation of a structural model for exchange rate determination, which is another complicated issue as documented in Meese and Rogoff (1983) and Edwards and Savastano (1999). As a result, time series methods have been partly replaced by nonparametric techniques, which allow us to test the hypothesis about the effectiveness of central bank interventions without relying on a structural model of exchange rate determination.

The main advantage of the event study analysis is that each event on the foreign exchange intervention can be analysed separately. Then, we can interpret the test results with special reference to the nature 
of the period over which the events are defined. Moreover, as being non-parametric, this approach does not require the imposition of a structural model for exchange rate determination. Finally, as argued by Fatum and Hutchison (1999), event study approach fits very well with the volatile nature of the exchange rate on a daily basis as well as with the clustered and sporadic nature of the interventions. Indeed, they find strong evidence that sterilized intervention in the US economy systematically affects the exchange rate; proving that the time series techniques failed to demonstrate the systematic relationship between foreign exchange interventions and the exchange rates.

Time-varying parameter framework: a methodology proposed. Other than these two commonly used methodologies, an alternative way to test the effectiveness of foreign exchange interventions may be to employ a time-varying parameter framework. As mentioned above, event study is a non-parametric approach in which a structural model need not be imposed. However, such an approach also implies that there is no explanation about why foreign exchange intervention is effective or which factors cause intervention to be more operative. On the other hand, although parametric, GARCH type models assume that the coefficients of the model, which explains the relationship between the exchange rate and the interventions, stay intact over time. However, especially for an emerging market like the Turkish economy, the macroeconomic environment is highly dynamic and subject to several structural changes. Based on this discussion, a time-varying parameter model, which would not face the problems mentioned above, would be appropriate to employ. Both the changing dynamics of the exchange rates and the channels through which the interventions are effective can be studied in such a set-up.

\section{Effects of intervention}

Event study. As argued by MacKinlay (1997), there are three stages in an event study. First, the event of interest is defined. At the second step, the event period is identified. Such a period consists of an event window, including prior event days, the event day(s), the post-event days, and the sample period. Finally, the design of the event study is established. In our case, after the foreign exchange intervention is conducted, the exchange rate dynamics both in terms of the volatility and the level are analysed on the basis of a particular measure of success; namely, volatility, smoothing and direction.

Events, post and pre-event windows: definitions. The event is defined as the period of days with official CBRT intervention in the foreign exchange rate market in one direction in terms of purchases or sales. The tranquility period, that is consecutive days of no intervention, is set as five days. Having defined the events, we classify them into four main groups: (1) the pure intervention purchase; (2) the intervention purchase with the auction in the same direction; (3) the pure intervention sale; (4) the intervention sale with the auction in the same direction. ${ }^{4}$ Furthermore, each category is also grouped in size such as; large, medium and small. As an event window, pre and post event window lengths of two, five and ten days are applied, and the five-day window is considered as the base scenario.

Successful event: definition. As consistent with the CBRT announcement, the main criterion to evaluate the success of intervention is the volatility criterion. Besides, two more criteria; namely the smoothing and the direction criterion are analysed in order to evaluate the possible side effects of these interventions. These three criteria can be defined as follows: (1) volatility criterion tests whether the volatility of the exchange rate has remained unchanged or decreased in the post event window compared to the pre event window after the CBRT interventions. If the volatility of the exchange rate after the related intervention has decreased, the intervention is market as a definitely successful event. On the other hand, if the volatility has remained unchanged, the intervention can also be classified as a successful event because the CBRT intervenes in the foreign exchange market seeing the excess volatility in the exchange rates in the particular intervention day compared to the pre-event window. Therefore, achieving the same exchange rate variation in the post event window as in the pre event window can also be evaluated as a success of the CBRT interventions. For this purpose, the variance test that compares the variances of the exchange rates in the pre and post event windows is applied. (2) The smoothing criterion tests whether the foreign exchange interventions in terms of purchases (sales) to the market result in a significantly lower Turkish lira appreciation (depreciation) in the post event period compared to the prior event period. The trend test is applied to assess the events in terms of the smoothing criterion. (3) The direction criterion

\footnotetext{
${ }^{4}$ We primarily focus on the success of the interventions; therefore, the pure auctions, whose primary aim is to accumulate international reserves, are not analysed.
} 
for the level of the exchange rate evaluates the changes in the direction of the movement in the exchange rate after the CBRT interventions. For this purpose, the non-parametric sign test for the mean is carried out. All of these tests are explicitly described in Appendix B. The descriptive statistics for the interventions are presented in Table 1, while the test results are presented in Table 2 and Table 3.

\section{Non-parametric mean and the trend test results}

Pure intervention purchase. There is only one event analysed in this group, the intervention on 2 December 2002. The variance test result point out that the volatility in the foreign exchange market has remained unchanged in the post-event window compared to pre event window, implying that the event is successful in terms of volatility criterion. In terms of the smoothing criterion, the event seems to have broken the appreciation trend in Turkish lira in the post-event window but it is statistically insignificant.

Intervention purchase with the auction in the same direction. These groups of interventions consist of large purchase interventions held in the second and third quarters of 2003. This period is interesting in the sense that all of the above mentioned interventions are followed by interest rate cut decisions of the CBRT. $^{5}$

Out of six events, none of the variance test statistics is statistically significant, implying that variation in the exchange rate has remained unchanged in the post-event window compared to the pre-event window. Although insignificant, two out of the six interventions lead to a decrease in the volatility. Besides, the events on 18 July and 25 September 2003 result in significantly higher exchange rate level following the corresponding interventions. In terms of smoothing criterion, trend test results point out the fact that none of the interventions significantly changes the trend of the exchange rate movement.

Pure intervention sale. There are two small-sized sale interventions in this group. In fact, in the sample period, sale interventions of the CBRT are generally in small-sized, indicating that these interventions are mainly used to give signals to the markets regarding the presence of CBRT. ${ }^{6}$

Both of the interventions result in lower exchange rate volatility in the foreign exchange markets, although only the intervention on 24 December 2002 is statistically significant. Therefore, only this intervention can be considered as a definitely successful event in five days window. Moreover, although insignificant, these interventions result in higher exchange rate level. The result of the smoothing test reveals that intervention on 24 December 2002 significantly reverses the trend of exchange rate movement; that is, the intervention changes the depreciation trend to an appreciation trend.

Intervention sale with the auction in the same direction. There are two events defined in this group. Both of the events have decreased the volatility, but none of them is statistically significant. However, these interventions are evaluated as successful events based on the reasoning explained before. As the direction criterion shows, the event on 5 October 2001 emerges as the only successful event. For the remaining event, the Turkish lira has continued to depreciate.

\section{Robustness checks}

As mentioned above, events based on 5-day window are set as the baseline. We provide a robustness check by applying the same methodology based on 2-day and 10-day windows. The results of these three alternative settings are discussed and compared below.

For the 2-day window, only the non-parametric mean test has been carried out. The test results are not consistent with the baseline results; events on 18 July 2003 and 25 September 2003 have no significant influence on the exchange rate level. For the 10-day window, on the other hand, consistent with the results in the baseline scenario, the purchase interventions on these two dates lead to a significantly higher exchange rate level. Moreover, the purchase intervention on 9 June 2003 and the pure sale interventions on 11 July 2002 and 24 December 2002 turn out to be definitely successful events in that volatility in the foreign exchange market following the interventions has significantly decreased (Table 3).

\section{Summary of the event study results}

Consistent with the spirit of the new exchange rate regime announced after the February 2001 financial crisis, the CBRT intervenes in the market in the case of excessive volatility. In this context, although

\footnotetext{
${ }^{5}$ Between the dates of 12 May 2003 and 25 September 2003, The CBRT purchased a total of 4.2 billion US dollars, and gradually decreased the overnight borrowing rate from 41 to $29 \%$.

${ }^{6}$ CBRT sold only 12 million US dollar in total in 2002.
} 


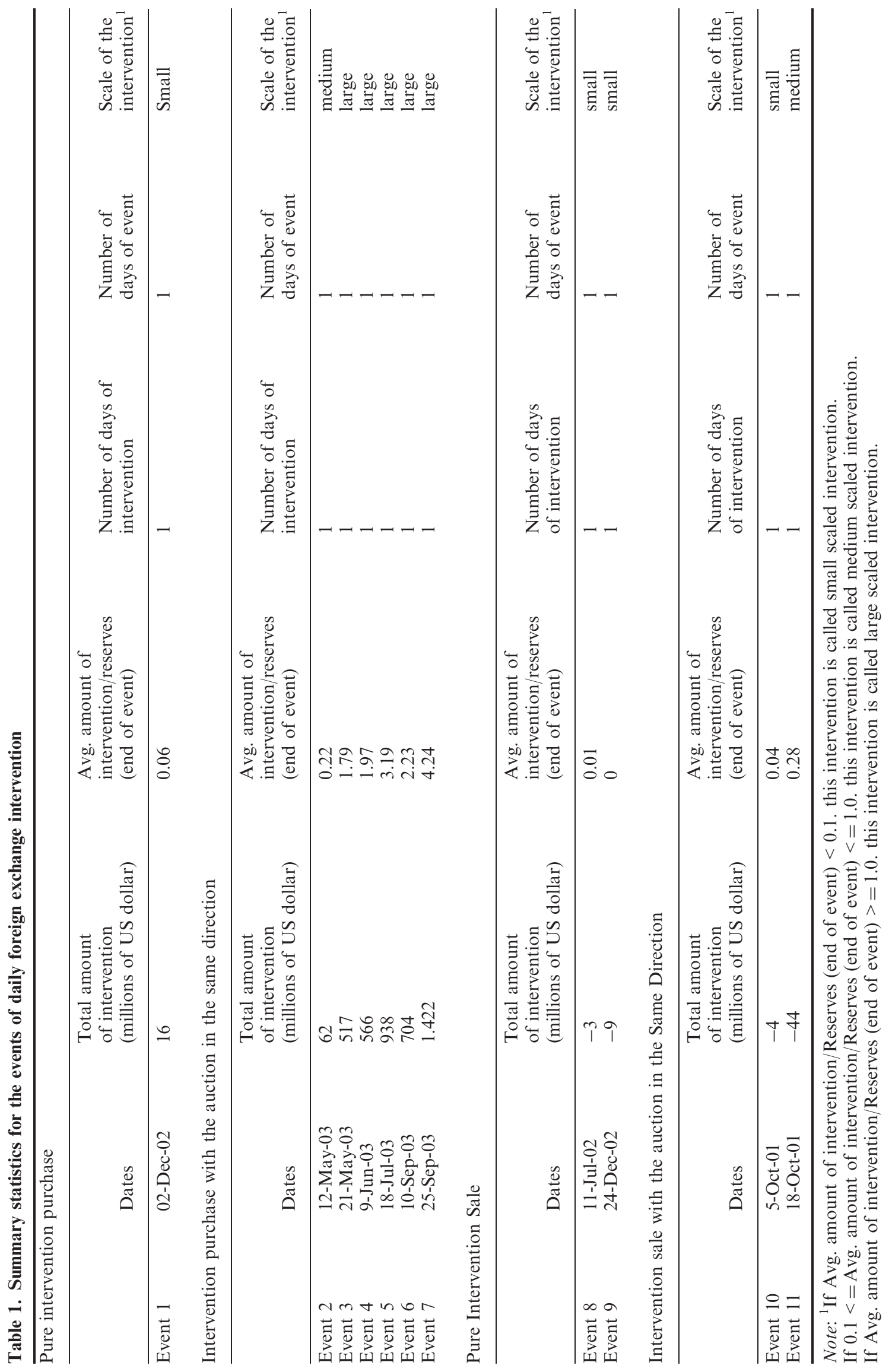




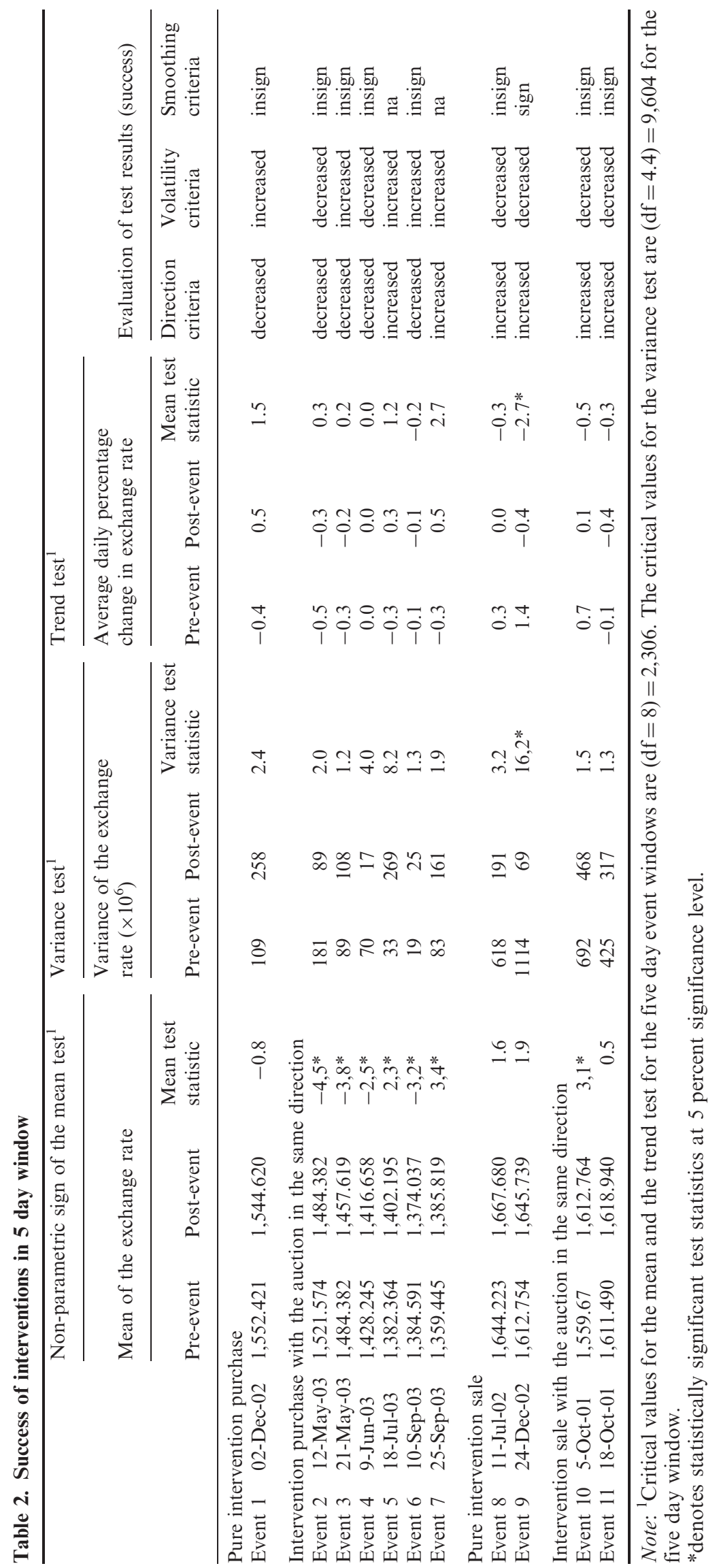




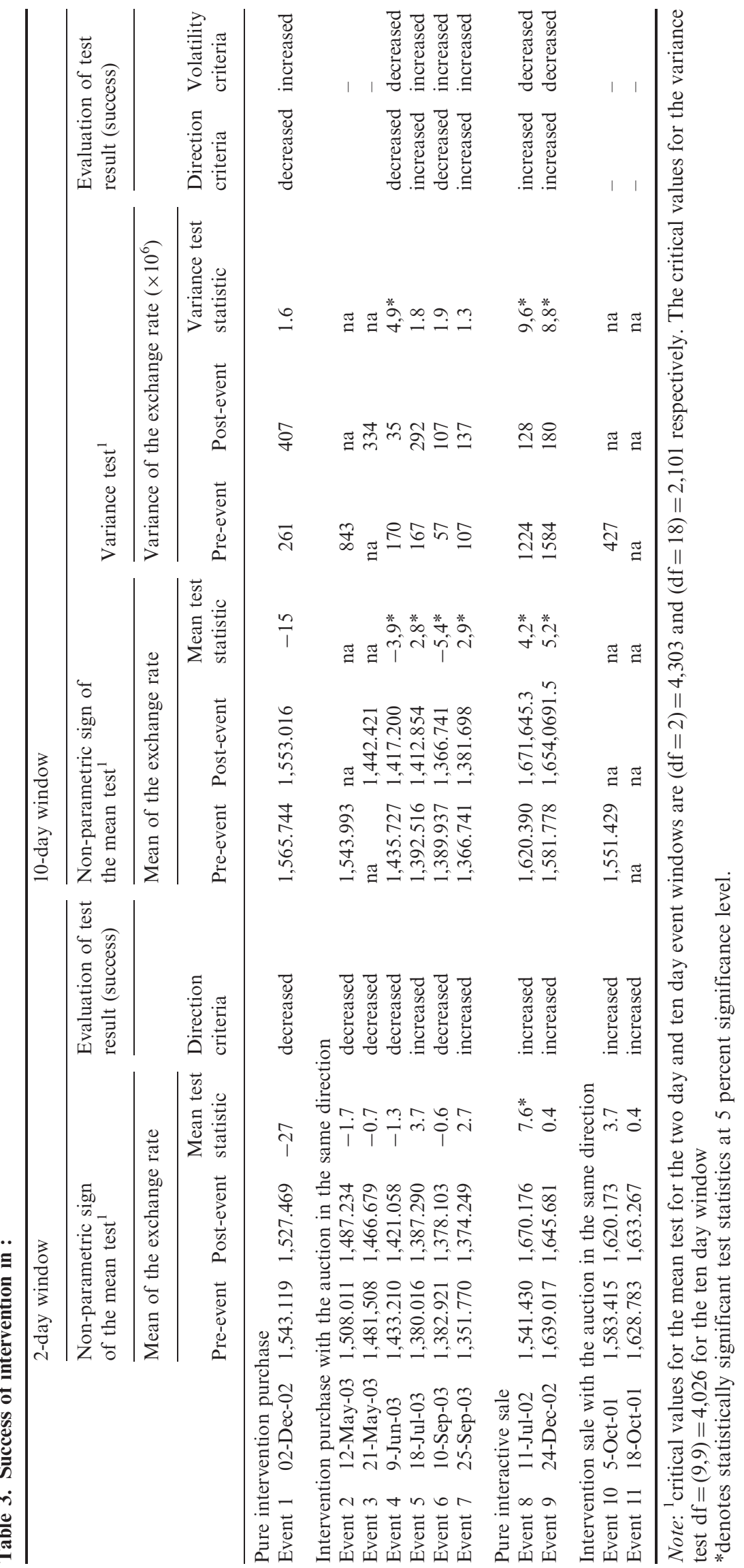


the findings of Akinci et al. (2005) suggest that CBRT conduct interventions to remove any excessive volatility in the market, the events study results partly support the effectiveness of these interventions.

The evaluation of the volatility criterion reveals that in the 5-days window, only the sale intervention on 24 December 2002 significantly lowers the volatility in the foreign exchange market. The results strengthen when the event window is enlarged to 10 days in that the volatility following the purchase intervention on 9 June 2003 and the sale interventions on 11 July 2002 and 24 December 2002 has significantly decreased. In sum, except these three interventions that are marked as definitely successful events, the CBRT interventions are partly successful in terms of volatility criterion. The exchange rate volatility has remained unchanged in the post-event window compared to pre-event window following the corresponding interventions. As a side result, it is found that the large purchase interventions on 18 July and 25 September 2003 have resulted in a significantly higher level of the exchange rate. Therefore, these results might indicate that the interventions have an influence on the level of the exchange rate as long as they are large and purchase interventions.

\section{Time-varying parameter model}

Time-varying parameter models are basically 'unobserved components' models and they should be estimated after they are presented in state space form. In this framework, the time varying parameters are unobserved for which a time series process should be assumed. Therefore, they should be included in the state equation. Formally, we specify and estimate the following state-space model:

$$
\begin{aligned}
& y_{t}=H_{t} x_{t}+w_{t} \\
& x_{t}=A_{t} x_{t-1}+v_{t}
\end{aligned}
$$

The first equation is the observation equation while the second one is the state equation based on the assumption that unobservable time varying parameters ( $x_{t}$ column vector) follow random walk process. $H_{t}$ includes the exogenous or predetermined variables that are expected to have an effect on the exchange rate. The disturbances, $w_{t}$ and $v_{t}$ are assumed to be independent white noise processes with $\operatorname{Var}\left(w_{t}\right)=R_{t}, \operatorname{Var}\left(v_{t}\right)=Q_{t}, \mathrm{E}\left(w_{s} v_{t}\right)=0$ for all s and $\mathrm{t}$. Finally, $A_{t}$ in the state equation is the identity matrix.

In the time-varying analysis, we employ fundamentals that are known to have an influence on the exchange rate level and the intervention variables. $D L U S D$ is the log difference form of the Turkish lira-US dollar exchange rate. TBILL is the secondary market Treasury bill rate to account for the relationship between the exchange rate and the interest rates. $S P R E A D$, used as a proxy for risk measurement, is the difference between returns on Turkish government bonds issued in international markets and the returns on US government bonds with similar maturities.

In the core model (Model 1), only the fundamentals are employed. Among intervention variables, to account for the asymmetric effects of purchases and sales on the exchange rate, these variables, which are denoted as INTP and INTS, are used separately in Model 2. Also, following Beine and Szafarz (2003), we have created several dummy variables: (i) in Model 3, size dummy variables are generated separately for large purchases (sales), DLAINTP (DLAINTS), and small purchases (sales), DSMINTP (DSMINTS), where large (small) intervention dummy variable takes the value of one if the amount of intervention/reserves ratio at day $t$ is greater (less) than the whole sample average of the daily intervention, and zero otherwise. (i) in Model 4, successive intervention dummy variable takes the value of one for the purchases (sales), DSUCINTP (DSUCINTS), if intervention at day $t$ is preceded by intervention in the same direction at day from $t-1$ to $t-15$, and zero otherwise; and isolated intervention dummy variable takes the value of one for the purchases (sales), DISOINTP (DISOINTS), if intervention at day $t$ is preceded by no intervention in a 15-day period;

As a result we have the following four alternative models:

$$
\begin{aligned}
\operatorname{DLUSD}_{t}= & \alpha_{o, t}+\alpha_{1, t} \text { DLUSD }_{t-1}+\alpha_{2, t} \text { TBILL }_{t} \\
& +\alpha_{3, t} \operatorname{SPREAD}_{t}+w_{t}
\end{aligned}
$$

(Model 1)

$$
\begin{aligned}
\operatorname{DLUSD}_{t}= & \alpha_{o, t}+\alpha_{1, t} \text { DLUSD }_{t-1}+\alpha_{2, t} \text { TBILL }_{t} \\
& +\alpha_{3, t} \text { SPREAD }_{t}+\alpha_{4, t} \text { DINTP }_{t} \\
& +\alpha_{5, t} \text { DINTS }_{t}+w_{t}
\end{aligned}
$$

(Model 2)

$$
\begin{aligned}
\operatorname{DLUSD}_{t}= & \alpha_{o, t}+\alpha_{1, t} \text { DLUSD }_{t-1}+\alpha_{2, t} \text { TBILL }_{t} \\
& +\alpha_{3, t} \text { SPREAD }_{t}+\alpha_{4, t} \text { DLAINTP }_{t} \\
& +\alpha_{5, t} \text { DSMINTP }_{t}+\alpha_{6, t} \text { DLAINTS }_{t} \\
& +\alpha_{7, t} \text { DSMINTS }_{t}+w_{t}
\end{aligned}
$$

(Model 3) 


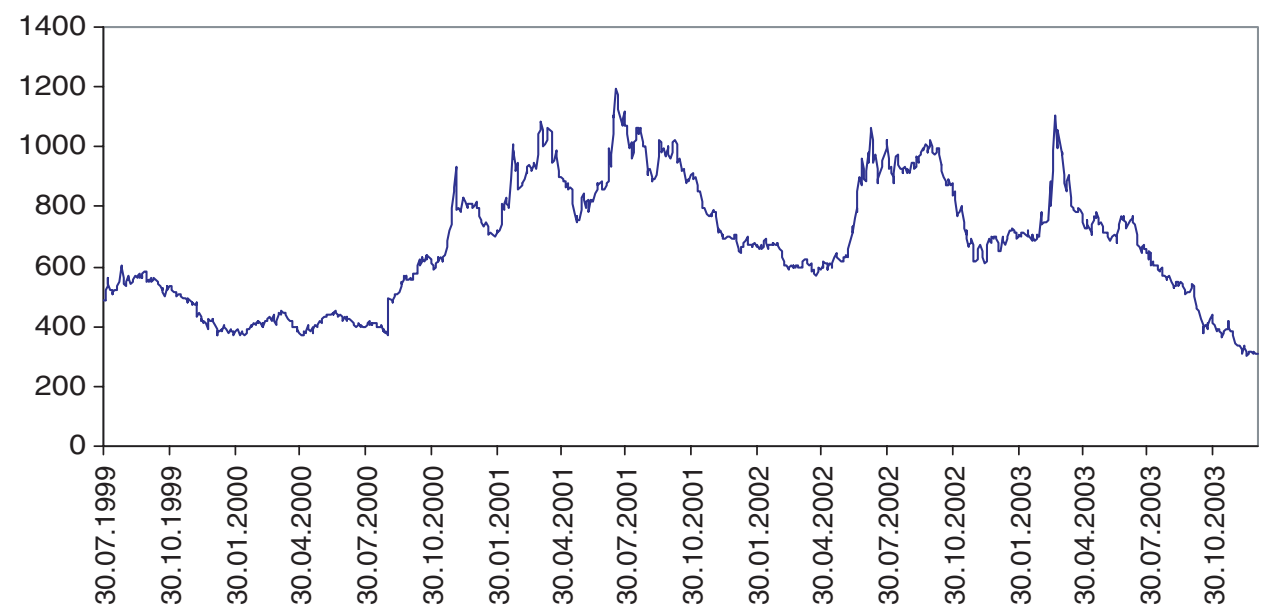

Source: JP Morgan

Fig. 1. EMBI + Turkey (2001-2003)

$$
\begin{aligned}
\text { DLUSD }_{t}= & \alpha_{o, t}+\alpha_{1, t} \text { DLUSD }_{t-1}+\alpha_{2, t} \text { TBILL }_{t} \\
& +\alpha_{3, t} \text { SPREAD }_{t}+\alpha_{4, t} \text { DISOINTP }_{t} \\
& +\alpha_{5, t} \text { DSUCINTP }_{t}+\alpha_{6, t} \text { DISOINTS }_{t} \\
& +\alpha_{7, t} \text { DSUCINTS }_{t}+w_{t}
\end{aligned}
$$

(Model 4)

The estimated parameters are presented in Figs. 2-5 in Appendix A. Since the Kalman filter is a recursive algorithm and sequentially updates the state vector according to past information, the initial path of the estimated parameters should be considered as the system's learning process, thus, could be ignored. Therefore, we have presented estimated time varying parameters starting from January 2002. Furthermore, given that most of the sale interventions refer to this period, estimation results related to the sale interventions should be evaluated carefully.

Estimation results reveal that, particularly after the second half of 2003, purchase interventions are more effective in influencing the exchange rate dynamics; that is Turkish lira depreciates following the purchase interventions. It should be noted that interventions in this period are characterized as large and isolated. Furthermore, Figs. 4(e) and 5(e) presented in Appendix A also confirm that large isolated purchase interventions are more successful in reversing the appreciation trend in the Turkish lira.

Concerning the relationship between the interest rate and the exchange rate, although a departure from conventional wisdom is observed, the results are consistent with the recent emerging market literature arguing that uncovered interest rate parity condition operates in an unconventional way, which is caused by the increased risk premium.
As is demonstrated in Blanchard (2004) and Favero and Giavazzi (2004), tighter monetary policy leads to higher real interest rates and raises concerns about the debt sustainability. Such a situation significantly increases the risk perceptions of the investors reflected by higher probability of default, which lead to capital outflows and eventually a depreciation of the domestic currency. The similar argument seems to hold for the Turkish economy in the post-crisis period, although the positive relationship has weakened after the first quarter of 2003. For the entire period, a decrease in the secondary market interest rates leads to a further appreciation of the Turkish lira as a result of the decrease in the perceived risk of the foreign investors. Such an explanation is also supported by the EMBI+ spread for Turkey, issued by JP Morgan, in which a steady downward trend has been observed, especially after the first quarter of 2003 (Fig. 1).

\section{Are empirical results robust to methodologies?}

There are some common results, which are robust to different methodologies employed throughout the study. First, both of the methods point out that the purchase interventions especially at the second half of 2003 seems to operate well. There are two possible explanations for this finding: it may be the case that interventions become successful only after the detrimental effects of the financial crises are completely over. Alternatively, there may be an asymmetry about the success of the interventions. If so, then the CBRT should not hesitate to intervene in the market and purchase USDs when there is increased volatility in an appreciation phase. 


\section{Results and Conclusions}

There is much literature regarding both the causes and the effectiveness of central bank interventions in the foreign exchange market. However, most of these studies stop short of extending their analysis to the emerging market economies. These economies are mostly characterized by having foreign exchange markets that exhibit excess sensitivity to capital flows. Also, most of these countries have started to implement either implicit or explicit forms of inflation targeting, which have reshaped the preferences towards exchange rate targets. Adding the highly dynamic macroeconomic environment and uncertainty about the operation of the uncovered interest parity condition to the picture, important insights may be gained by studying foreign exchange interventions in these economies.

Taking the above discussion as the starting point, this study analyses the effectiveness of foreign exchange interventions for the Turkish economy conducted by the CBRT in the post-crisis period.

Both methodologies, event study and time-varying parameter models, point out that the purchase interventions that took place in the second half of 2003 seem to be relatively more effective. Bearing in mind that these actions are mostly in the form of large interventions, there is a policy implication: the CBRT should not hesitate to intervene in the market in the form of large purchases. Finally, the time-varying parameter estimates show that, for the entire period, the uncovered interest rate parity condition operates in an unconventional way, which is caused by the risk premium channel. There are two points that we have to pay attention to in interpreting these results. First, the period witnessed mostly rate cuts. Thus, we cannot have a clear picture about the operation of UIP when the CBRT tightens its policy. Next, excluding the period right after the crisis, the Turkish lira was consistently in an appreciation trend. Again, we cannot confirm robust policy implications if there is excessive volatility on a depreciation trend that would induce the CBRT to intervene in the market.

\section{Acknowledgements}

We thank Fatih Ozatay, Mark Griffiths and participants in an informal departmental seminar for valuable discussions, comments, and suggestions. We are also grateful to the Markets Department of the Central Bank of Turkey for providing us with the data. The views in this paper, and any errors and omissions, should be regarded as those of the authors, do not necessarily reflect the individuals listed above, and the Central Bank of the Republic of Turkey.

\section{References}

Agcaer, A. (2003) Dalgalı kur rejimi altında Merkez Bankası müdahalelerinin etkinliği: Türkiye üzerine bir çalışma (Effectiveness of Central Bank interventions under the floating exchange rate regime: Turkish experience), Central Bank of Turkey, Ankara.

Akinci, O., Culha, O. Y., Ozlal, U. and Sahinbeyoglu, G. (2005) The effectiveness of foreign exchange interventions under floating exchange rate regime for the Turkish economy: a post-crisis period analysis, Central Bank of Turkey, Working Paper, No.05/05.

Arize, A. C. and Malindretos, J. (1997) Effects of exchange rate variability on inflation variability, Applied Economics Letters, 4, 453-7.

Beine, M. and Szafarz, A. (2003) The design of effective central bank interventions: the yen/dollar case, Working Paper, CEB 03/008.

Bergin, P. R. (2004) How well can the new open economy macroeconomics explain the exchange rate and the current account?, NBER Working Paper, No: 10356.

Blanchard, O. (2004) Fiscal dominance and inflation targeting: lessons from Brazil, NBER Working Paper, No. 10389.

Bonser-Neal, C. and Tanner, G. (1996) Central bank intervention and the volatility of foreign exchange rates: evidence from the options market, Journal of International Money and Finance, 15, 853-78.

Bonser-Neal, C., Roley, V. and Sellon, G. H. Jr. (1998) Monetary policy actions, intervention, and exchange rates: a reexamination of the empirical relationships using federal funds rate target data, Journal of Business, 71, 147-77.

Domac, I. and Mendoza, A. (2002) Is there room for forex interventions under inflation targeting framework? Evidence from Mexico and Turkey, CBRT, Discussion Papers, December.

Dominguez, K. M. and Frankel, J. A. (1993) Does foreign exchange intervention matter? The portfolio effect, American Economic Review, 83, 1356-69.

Dominguez, K. M. (1998) Central bank intervention and exchange rate volatility, Journal of International Money and Finance, 17, 161-90.

Edison, H. J. (1993) The effectiveness of central bank intervention: a survey of the literature after 1982. Special Papers on International Econnomics 18, Princeton University.

Edwards, S. and Savastano, M. A. (1999) Exchange rates in emerging economies: what do we know? What do we need to know, NBER Working Paper No: 7228.

Fatum, R. and Hutchison, M. M. (1999) Is sterilized foreign exchange intervention effective after all? An event study approach, EPRUs Working Paper Series, Santa Cruz, Working Paper No.487.

Fatum, R. (2000) On the effectiveness of sterilized foreign exchange intervention, SCCIE Working Paper No: 99-2. 
Fatum, R. and Hutchison, M. M. (2003) Is sterilized foreign exchange intervention effective after all? An event study approach, The Economic Journal, 113, $390-411$.

Favero, C. and Giavazzi, F. (2004) Inflation targeting and debt: lessons from Brazil, NBER Working Paper, No. 10390.

Guimaraes, R. and Karacadag, C. (2004) The empirics of foreign exchange intervention in emerging markets: the cases of Mexico and Turkey, IMF, Working Paper No. $04 / 123$.

Herrera, A. M. and Ozbay, P. (2005) A dynamic model of central bank intervention, Central Bank of Turkey, Working Paper, No.05/01.

Hung, J. H. (1991) Noise trading and the effectiveness of sterilized foreign exchange intervention, Federal Reserve Bank of New York Research Paper, No. 9111.

Hung, J. H. (1997) Intervention strategies and exchange rate volatility: a noise trading perspective, Journal of International Money and Finance, 16, 779-93.

Kaminsky, G. L. and Lewis, K. (1996) Does foreign exchange intervention signal future monetary policy, Journal of Monetary Economics, 37, 285-312.

Kim, S., Kortian, T. and Sheen, J. (1999) Central bank intervention and exchange rate volatility-Australian evidence, Journal of International Financial Markets, Institutions and Money, 10, 381-405.

\section{Appendix A}

\section{Model 1}

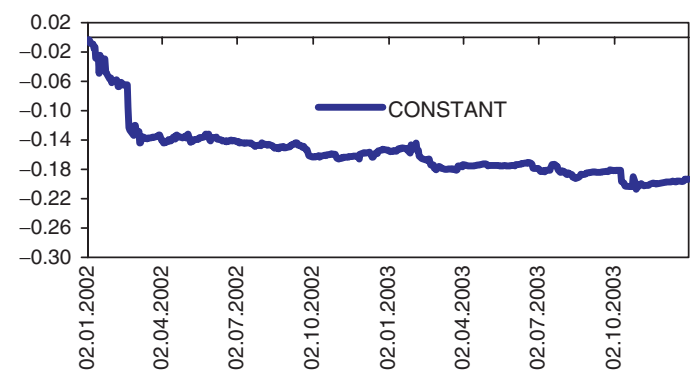

C

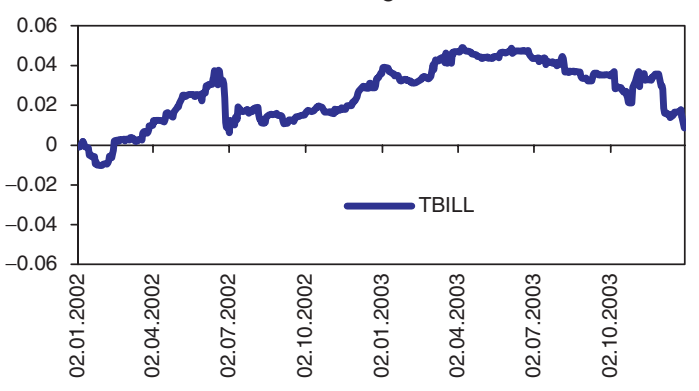

Kim, S.-J. (1999) Do macro-economic news announcement affect the volatility of the foreign exchange rates? Some evidence from Australia, Applied Economics, 31, 1511-21.

Lewis, K. (1995) Are foreign exchange intervention and monetary policy related and does it really matter?, NBER Working Paper No. 4377.

MacKinlay, A. C. (1997) Events studies in economics and finance, Journal of Economic Literature, XXXV, 13-39.

McLaren, Z. (2002) The effectiveness of reserve bank of Australia foreign exchange intervention, The University of Melbourne, Economics Department Research Paper, No. 849.

Meese, R. and Rogoff, O. (1983) The out-of sample failure of empirical exchange rate models, in Exchange Rate and International Macroeconomics (Ed.) J. Frenkel, University of Chicago Press, Chicago.

Ramchander, S. and Sant, R. R. (2002) The impact of federal reserve intervention on exchange rate volatility: evidence from the futures market, Applied Financial Economics, 12, 231-40.

Sarno, L. and Taylor, M. P. (2001) Official intervention in the foreign exchange market: is it effective and, if so, how does it work?, Journal of Economic Literature, 39, 839-68.

Spolander, M. (1999) Measuring exchange market pressure and central bank intervention, Bank of Finland Studies E: 17.

Fig. 2. Time varying parameter estimates for Model 1
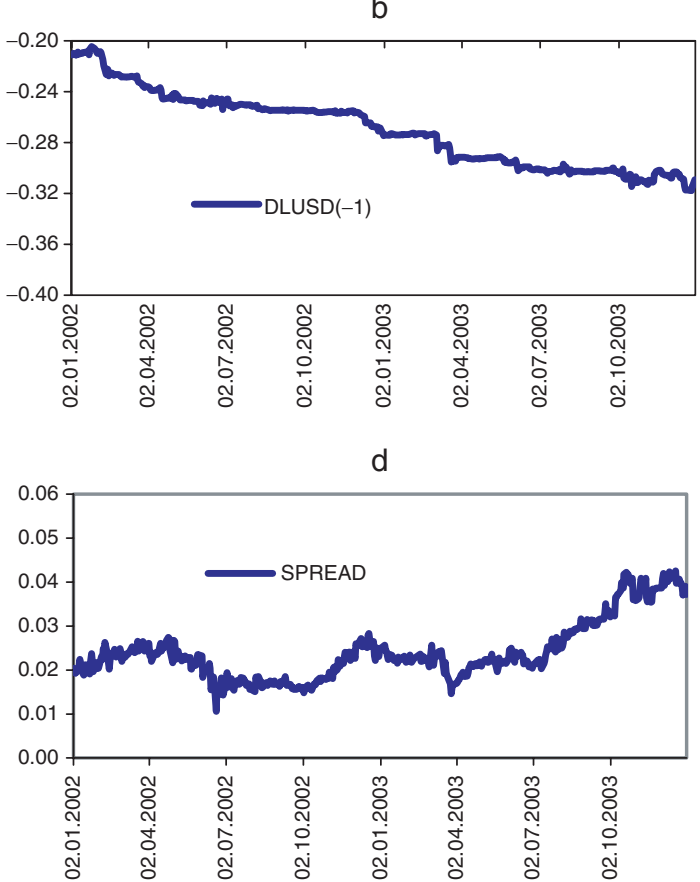
Model 2
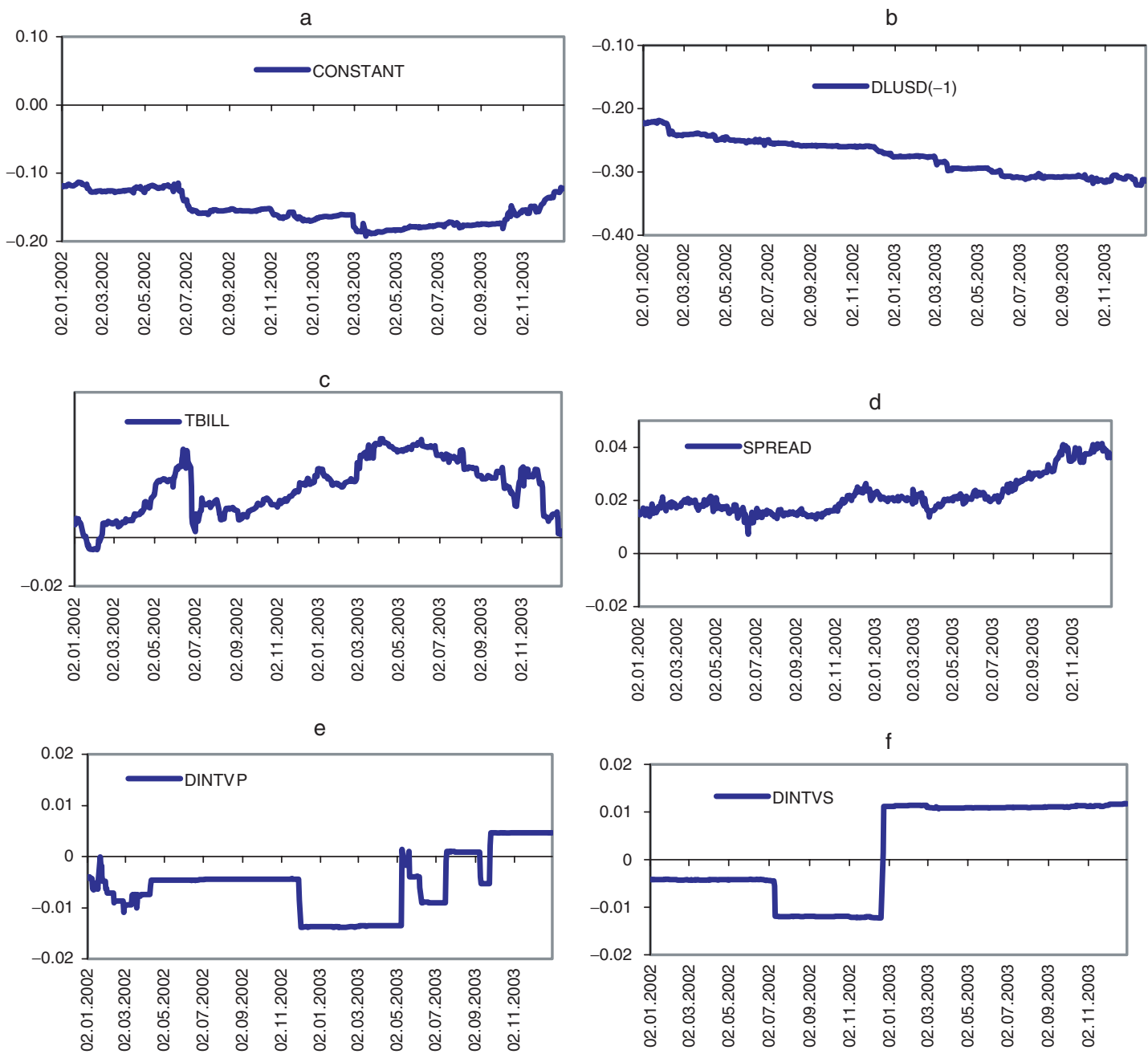

Fig. 3. Time varying parameter estimates for Model 2 
Model 3
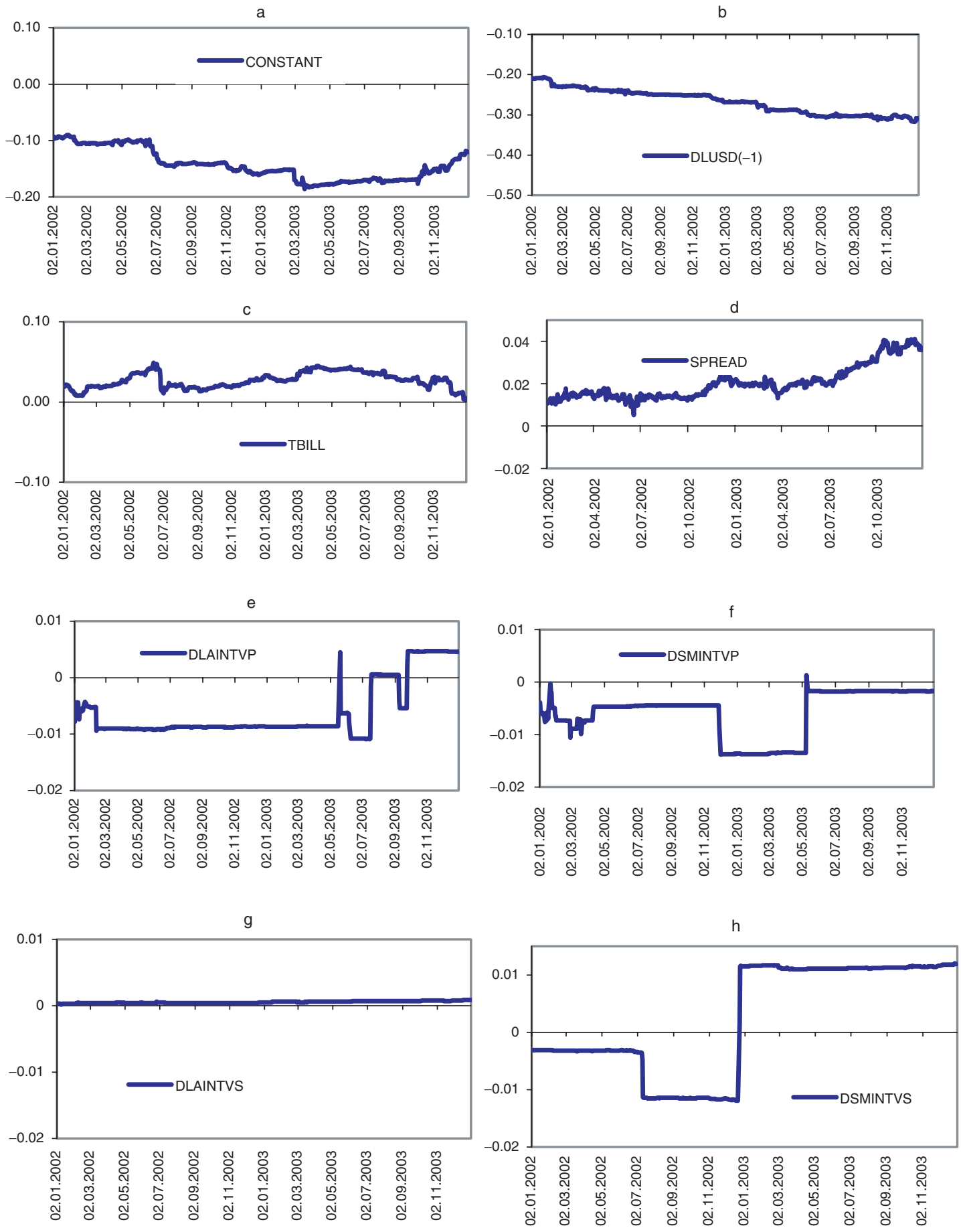

Fig. 4. Time varying parameter estimates for Model 3 

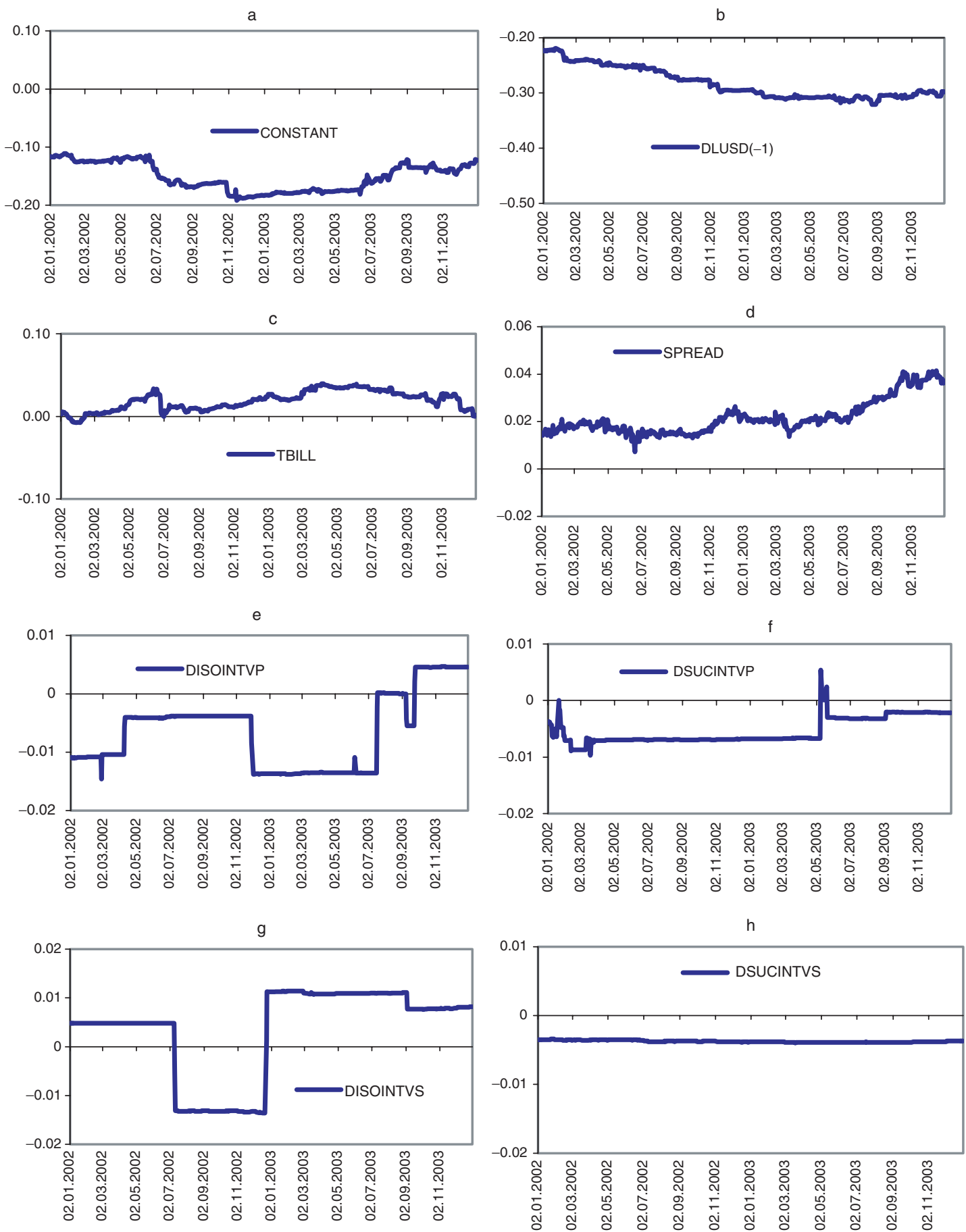

Fig. 5. Time varying parameter estimates for Model 4 


\section{Appendix B}

Formulas for the event study analysis

Mean test

$$
\begin{aligned}
\mathrm{X}= & (\mathrm{B} 2-\mathrm{A} 2) /(\mathrm{SQRT}(((\mathrm{A} 1 * \mathrm{~A} 3+\mathrm{B} 1 * \mathrm{~B} 3) \\
& /(\mathrm{A} 1+\mathrm{B} 1-2)) *(1 / \mathrm{A} 1+1 / \mathrm{B} 1)))
\end{aligned}
$$

$\mathrm{A} 1=$ number of observations before

$\mathrm{B} 1=$ number of observations after

$\mathrm{A} 2=$ mean of the exchange rate before

$\mathrm{B} 2=$ mean of the exchange rate after

$\mathrm{A} 3=$ variance of the exchange rate before $\mathrm{B} 3=$ variance of the exchange rate after degrees of freedom $=\mathrm{A} 1+\mathrm{B} 1-2$

$$
\begin{aligned}
& \text { Ho: } X=0 \\
& \text { Ha }: X \neq 0
\end{aligned} \Rightarrow \text { students } t \text { distribution }
$$

Variance test

$$
\mathrm{Y}=\max (\mathrm{A} 1, \mathrm{~B} 1) / \min (\mathrm{A} 1, \mathrm{~B} 1)
$$

$\mathrm{A} 1=$ number of observations before $\mathrm{B} 1=$ number of observations after $\mathrm{A} 3=$ variance of the exchange rate before
$\mathrm{B} 3=$ variance of the exchange rate after degrees of freedom $=(\mathrm{A} 3-1, \mathrm{~B} 3-1)$

$$
\begin{aligned}
& \text { Ho: } Y=0 \\
& \text { Нa }: Y>0
\end{aligned} \Rightarrow \text { F distribution }
$$

Trend test

$$
\begin{aligned}
\mathrm{X}= & (\mathrm{B} 2-\mathrm{A} 2) /(\mathrm{SQRT}(((\mathrm{A} 1 * \mathrm{~A} 3+\mathrm{B} 1 * \mathrm{~B} 3) \\
& /(\mathrm{A} 1+\mathrm{B} 1-2)) *(1 / \mathrm{A} 1+1 / \mathrm{B} 1)))
\end{aligned}
$$

$\mathrm{A} 1=$ number of observations before

$\mathrm{B} 1=$ number of observations after

A2 $=$ average daily percentage change in exchange rate before

$\mathrm{B} 2=$ average daily percentage change in exchange rate after

$\mathrm{A} 3=$ variance of the daily percentage change in exchange rate before

$\mathrm{B} 3=$ variance of daily percentage change in exchange rate after

degrees of freedom $=\mathrm{A} 1+\mathrm{B} 1-2$

Ho : $X=0$

Ha : $X \neq 0 \Rightarrow$ students $t$ distribution 